Lepr Rev (1996) 67, 253-259

\title{
Editorial
}

\section{THE MANAGEMENT OF ERYTHEMA NODOSUM LEPROSUM: CURRENT AND FUTURE OPTIONS}

Erythema nodosum leprosum (ENL) is the most serious immunological complication affecting patients with multibacillary (MB) leprosy. Before the introduction of multidrug therapy (MDT) as many as $50 \%$ of lepromatous leprosy (LL) and $30 \%$ of borderline (BL) patients were affected. ${ }^{1}$ The introduction of WHO-MB-MDT has reduced both the frequency and severity of ENL and this reduction is attributable to the clofazimine component of MDT since multibacillary patients treated with drug regimes without clofazimine continued to experience high levels of ENL. ${ }^{2}$ There are few published data on the current frequency of ENL. In Ethiopia incidence rates of $2.7 \%$ and $11 \cdot 1 \%$ were found in BL and LL patients respectively ${ }^{3}$ but higher incidences have been reported in SE Asia and Brazil. For the individual patient ENL is serious and produces considerable morbidity particularly in the chronic recurrent form. This editorial reviews the evidence for the various treatments of ENL with particular emphasis on data derived from trials that used a randomized controlled design.

The pathology of ENL is now understood to involve both immune complex deposition and dysfunction of cell-mediated immunity. The principal event involves deposition of antigen-antibody complexes in tissue, ${ }^{4}$ with activation of complement, development of local inflammation, neutrophil polymorph migration to the site $^{5}$ and local release of tissue damaging enzymes. ${ }^{6}$ Macrophages and $\mathrm{T}$ cells are activated ${ }^{7}$ and circulating TNF $\alpha$ levels are elevated during ENL episodes. ${ }^{8}$

ENL affects many organs and this should be remembered when assessing a patient with this complication. It is important to ask about symptoms indicating involvement of skin, nerves, eyes, joints, testes, kidneys and lymphatics and then to examine for evidence of on-going disease. In mild cases of ENL the skin lesions do not cause discomf ort, but in more severe cases lesions are active with pain, pustule formation and ulceration.

The management of ENL is guided by the need to control the acute inflammation and neuritis, ease the pain, halt eye damage and prevent further attacks. In all cases of ENL, patients should rest and receive anti-inflammatory medication. If there is any evidence of nerve tenderness or active neuritis affected limbs should be rested, and splinted in severe cases. The eyes should be caref ully monitored. If there is any evidence of irido-cyclitis treatment with steroid and atropine eye drops should be started.

Mild cases of ENL may be managed with anti-inflammatory medication and rest. There is no data showing an advantage for any particular anti-inflammatory. In a double-blind trial acetylsalicylic acid (Aspirin) $400 \mathrm{mg} 6$ hourly was shown to be helpf ul, 
producing improvement in $48 \%$ lesions at $48 \mathrm{hr} .{ }^{9}$ A double-blind controlled trial comparing Aspirin ( $1 \mathrm{~g} 8$ hourly), indomethacin ( $50 \mathrm{mg} 8$ hourly) and chloroquine ( $250 \mathrm{mg}$ 8 hourly) in ENL showed no significant difference in the relief of symptoms obtained with any of these three drugs, although the time to relief of neuritis was significantly longer in the group treated with indomethacin (mode of 14 days for indomethacin, as compared with 7 days for the other two drugs). Patients treated with Aspirin had fewest side-effects (29\%), versus $63 \cdot 6 \%$ for indomethacin and $58 \cdot 5 \%$ for chloroquine. Patients treated with indomethacin had the lowest incidence of visual disturbance which the author attributes to early absorption of the exudate associated with ENL. ${ }^{10}$ Other nonsteroidal anti-inflammatory agents have not been evaluated in randomized controlled trials in mild ENL. In an open unblinded study, colchicine was used with some success, with relief of acute symptoms starting within 24 hours and a maintenance dose suppressing further attacks. ${ }^{11}$ A double-blind controlled trial in India compared Aspirin and colchicine in both mild and moderate ENL. In mild disease both drugs were equally effective but in moderate disease colchicine was superior, being far more effective in the relief of nerve pain (50\% relief with colchicine, $18 \cdot 2 \%$ with Aspirin) and joint pain $\left(81 \cdot 8 \%\right.$ relief with colchicine, $34 \cdot 8 \%$ with Aspirin). ${ }^{12}$ However in the subsequent internally controlled trial colchicine treatment had no effect on the steroid requirements of patients with chronic ENL and diarrhoea was a serious and limiting side-effect. ${ }^{13}$ Other workers report that colchicine is not a useful alternative treatment in ENL. ${ }^{14}$

Prednisolone is the anti-inflammatory of choice in moderate and severe ENL. Most doctors recommend a starting dose of $60 \mathrm{mg}^{15,16}$ but doses up to $200 \mathrm{mg}$ have been used. ${ }^{14}$ However no comparisons of different starting regimes have been made. The response to high dose steroids is usually rapid and the steroid dose should be reduced to $30 \mathrm{mg}$ daily as soon as possible and then tapered down over the next two months. Although steroid treatment is effective, ENL patients are at great risk of becoming steroid dependent, especially those with chronic ENL.

Thalidomide is a controversial yet highly effective drug in the management of acute severe and recurrent ENL. In vitro work has shown that it enhances degradation of TNF $\alpha$ mRNA. ${ }^{17}$ In a Brazilian study reduction of serum TNF $\alpha$ levels in patients with ENL was accompanied by an improvement in clinical symptoms. ${ }^{18}$ Thalidomide also acts on $\mathrm{T}$ cells reducing the number of circulating CD4 cells and increasing CD8 numbers. ${ }^{19}$ The placebo controlled trial by Sheskin et al., ${ }^{20}$ showed a highly significant benefit from thalidomide in acute ENL with $86 \%$ of patients improving clinically. The response to thalidomide is rapid, usually within $8-48 \mathrm{hr}^{21}$ A later uncontrolled study in acute ENL showed that thalidomide produced a significant decrease in both the dose and length of prednisolone requirements. ${ }^{22} \mathrm{~A}$ WHO coordinated double-blind trial compared thalidomide with Aspirin; thalidomide was consistently superior to Aspirin producing faster resolution of fever, greater regression of skin lesions and a decreased chance of further reactions. ${ }^{9}$ The value of thalidomide in chronic ENL was suggested in an uncontrolled study by Levy ${ }^{23}$ who showed a significant decrease in the frequency of admissions for ENL after taking thalidomide. A double-blind cross-over study in Malaysian patients with severe ENL showed that $90 \%$ improved whilst taking the drug permitting a concomitant $60 \%$ decrease in steroid requirement. ${ }^{24}$ Pearson \& Vedagiri ${ }^{25}$ compared thalidomide with placebo in mild ENL, finding clinical improvement, reduction in fever and anti-inflammatory requirements with thalidomide. They also commented that patients preferred thalidomide to other drugs. Thalidomide is 
reported as having few minor side-effects, notably mucosal dryness, rashes and constipation but interestingly, in the blinded trials in leprosy patients, there were no differences in side-effects reported between the treated and control groups. ${ }^{9,20,25}$ In a study of 94 Indian patients dose-related oedema was reported as the commonest sideeffect. $^{22}$

Although the clinical evidence demonstrating the usef ulness of thalidomide in ENL is excellent, there are serious problems associated with its use. These include its teratogenicity, possible neurotoxicity and limited availability. The teratogenicity of thalidomide when given in early pregnancy has been well described. Physicians have a heavy burden of responsibility to ensure that firstly a woman is not newly pregnant and secondly can be adequately protected against pregnancy whilst taking thalidomide. WHO recommends that only males and postmenopausal women should be treated with thalidomide. When prescribing thalidomide to men it is also important to warn the patient against sharing the drug with friends or relatives whom he feels might benefit from treatment. Guidelines have been produced in the UK for the use of thalidomide and emphasize the importance of obtaining written consent from patients before prescribing this drug as well as ensuring that patients understand the potential risks and are able to comply with prescribing instructions. ${ }^{26}$ The other serious side-effect of thalidomide is peripheral neuropathy. This has been well described in nonleprosy patients treated with thalidomide. In prurigo nodularis the risk of axonal induced neuropathy approaches $100 \% .{ }^{27}$ However peripheral neuropathy does not appear to be a major side-effect in leprosy patients and several workers have commented on its rarity. ${ }^{28}$ There are several possible explanations: leprosy patients may already have neuropathy and so do not complain of paraesthesiae; iatrogenic neuropathy may not have been looked for in leprosy, or these patients may be relatively resistant to thalidomide-induced peripheral neuropathy. ${ }^{29}$ The first two explanations seem unlikely. Leprosy patients do experience paraesthesiae and most main leprosy centres check voluntary muscle and sensory nerve function routinely. In a small electrophysiological study thalidomide treatment was associated with arrest of nerve damage as measured by motor conduction velocities. ${ }^{30}$ However this is clearly an important issue and as Jakeman \& Smith $^{31}$ have suggested, a study involving careful observation, nerve conduction studies and nerve biopsy of a series of thalidomide-treated patients is badly needed.

The role of clofazimine in the management of chronic ENL is well established. Its anti-inflammatory effect on ENL was initially noted as a beneficial side-effect when using clofazimine as an antibacterial agent. ${ }^{32}$ Subsequent non randomized uncontrolled trials by Imkamp ${ }^{33,34}$ and Hastings ${ }^{35}$ showed that clofazimine treatment of patients with severe ENL lead to a significant reduction in steroid requirement. In Malaysia, a placebo-controlled cross-over trial of $300 \mathrm{mg}$ clofazimine daily in 10 patients with moderate ENL showed a decrease in requirement for anti-inflammatory medication and a reduction in clinical activity whilst on clofazimine ${ }^{36}$ Clofazimine is not as effective or as rapidly acting as prednisolone or thalidomide ${ }^{37}$ and its major role is in preventing further attacks and decreasing steroid dependence. Imkamp ${ }^{34}$ reported that with longterm clofazimine therapy many of her patients were able to resume employment. Clofazimine accumulates in the skin and gastrointestinal tract so accounting for the major side-effects, skin pigmentation and abdominal symptoms, notably diarrhoea and abdominal pain. The skin pigmentation and dryness develop within a few weeks of starting treatment and may take two or more years to fade. ${ }^{38}$ 
So what can be offered to the patients with ENL? Mild attacks of ENL can be treated with analgesics. Steroids should be reserved for moderate and severe attacks or where there is evidence of neuritis. The recurrent nature of ENL means that patients started on steroids are at risk of becoming steroid dependent and every effort should be made to keep steroid courses as short as possible whilst relieving clinical symptoms. Thalidomide is probably the drug of choice for male patients with severe or recurrent ENL. In centres where thalidomide is available treatment with thalidomide should be instigated early. Several authors have reported that the response to thalidomide was blunted and slower in patients already receiving steroids, suggesting an adverse interaction between thalidomide and steroids. ${ }^{22,39,40}$ For premenopausal women steroids and clofazimine should be used. It is important to use a large enough dose of clofazimine to prevent recurrence. Pettit ${ }^{41}$ reported no significant benefit for clofazimine $100 \mathrm{mg}$ daily in a controlled study in patients with severe ENL needing high doses of steroids. The apparent treatment failure was probably due to inadequate dosing with clofazimine. Doses of up to $300 \mathrm{mg}$ can saf ely be used for several months. ${ }^{42}$ Charting the frequency of attacks and episodes requiring prednisolone will help both physician and patient assess the effect of clofazimine.

It is surprising that no randomized controlled trials of new therapies for ENL have been published in the last twenty years. Even if only $10 \%$ of lepromatous patients are experiencing ENL this is still a large problem on a global scale and there is an urgent need for multicentre trials. The current available treatments all have drawbacks and are not always effective, in three thalidomide studies failure rates of $7 \cdot 4 \%$, ${ }^{22}$ and $10 \%{ }^{24}$ patients and $8 \cdot 2 \%$ episodes ${ }^{20}$ were reported. Mishra \& Girdhar reported 8 treatment failures in a series of 30 patients with chronic ENL managed with clofazimine 100$300 \mathrm{mg}$ per day. ${ }^{43}$ The underlying pathology of ENL has several components and no single immune defect is consistently present in patients with ENL. Immune complex deposition can only be demonstrated in $50 \%$ of patients, not all LL patients have raised TNF $\alpha$ levels during episodes of ENL and $36 \%$ of skin biopsies do not have a neutrophil infiltration. ${ }^{44}$ Whilst timing of sampling accounts for some of these differences they may also reflect a balance of different humoral and cell-mediated dysfunction. This has implications for the development and testing of new treatments and a wide range of immunosuppressive drugs, acting on both the humoral and cell-mediated immune systems should be considered.

The tissue damaging neutrophil infiltration of blood vessels in the systemic vasculitides has some similarities with the skin biopsy of ENL. Intravenous methylprednisolone is now well established as an initial treatment in vasculitis and its anti-inflammatory action probably reduces vessel inflammation. ${ }^{45}$ One might postulate that methylprednisolone could have a similar effect in ENL and perhaps early methylprednisolone treatment could ameliorate ENL. A controlled study would be required to test this hypothesis.

One might predict that plasma exchange would be useful in ENL, by binding and removing immune complexes from the circulation. It has been used successfully in four patients who had failed with conventional ENL treatment, and no relapses occurred in the four years following treatment. ${ }^{46}$ However plasma exchange requires expensive technology and safe blood products, so making it unsuitable for most leprosy endemic countries. In a series of randomized trials neurologists have shown that plasma exchange and intravenous immunoglobulin (IgG) have similar efficacy in the treatment of Guillain-Barre Syndrome. ${ }^{47}$ Intravenous immunoglobulin has anti-inflammatory and 
immunoregulatory effects including interference with Fc receptor function, downregulation of antibody production, alterations in $\mathrm{T}$-cell function and cytokine inhibition. ${ }^{48}$ These immunomodulatory actions and the experience in the treatment of Guillain-Barre Syndrome suggest that a trial of IgG in ENL would be useful.

Cyclosporin A was first proposed as a treatment for ENL by Mshana ${ }^{49}$ in 1982, and has been shown in vitro to restore suppressor cell activity during ENL. ${ }^{50}$ It is used extensively in transplant patients to prevent graft versus host disease. Three patients with chronic steroid dependent ENL have been treated with cyclosporin A and excellent results were obtained in two, both of whom had failed to respond to second courses of thalidomide. ${ }^{51}$ A larger, randomized trial is needed to confirm these preliminary findings.

$\mathrm{TNF} \alpha$ antibody treatment is another modality that should be tested. TNF $\alpha$ antibodies have been developed for human use and their human safety has now been established. ${ }^{52}$ Randomized controlled trials have established the value of TNF $\alpha$ antibody treatment in patients with rheumatoid arthritis. ${ }^{53,54}$ In a trial in Addis Ababa TNF $\alpha$ antibodies had a highly significant effect in ameliorating the Jarisch Herxheimer reaction, a TNF $\alpha$ dependent phenomenon. ${ }^{55}$ The clear association between elevated serum $\mathrm{TNF} \alpha$ levels and the development of ENL suggests that binding and removing TNF $\alpha$ from the circulation might improve ENL.

Tenidap is a new agent from a class of drugs that act both as anti-inflammatory agents and disease modifying drugs in rheumatoid disease. Tenidap inhibits neutrophilmediated damage and the synthesis and release of cytokines including TNF $\alpha$. In numerous double-blind studies in patients with rheumatoid arthritis it has been shown to be equivalent to treatment with second-line agents such as hydroxychloroquine. ${ }^{56}$ Its immunological and disease modifying properties make it another agent appropriate for testing in ENL.

Trials are also needed to assess whether adjunct therapy can ease the symptoms of mild ENL. A nonplacebo controlled trial in India showed that oral zinc reduced the frequency, duration and severity of ENL episodes and this should be tested formally. ${ }^{57}$

The better understanding of the pathological processes underlying ENL and the development of new treatments for other immune-mediated conditions mean that there are now good prospects for testing new drugs in ENL and finding better and more effective treatments for patients. The challenge is to find people able to draft protocols and co-ordinate centres willing to participate in good trials.

\section{Acknowledgment}

I would like to thank Professor A. D. M. Bryceson and Dr A. S. Malin for their helpful critical readings of this manuscript.

Hospital for Tropical Diseases \&

Diana N. J. Lockwood

London School of Hygiene \& Tropical Medicine

\section{References}

1 Ridley DS, Waters MFR. Significance of variations within the lepromatous group. Lepr Rev, 1969; 40: 14352 . 
${ }^{2}$ Cellona RV, Fajardo TT, Jr., Kim DI, Hah YM, Ramasoota T, Sampattavanich S, Carrillo MP, Abalos RM, dela Cruz EC, Ito T, et al. Joint chemotherapy trials in lepromatous leprosy conducted in Thailand, the Philippines, and Korea. Int J Lepr Other Mycobact Dis, 1990; 58: 1-11.

3 Becx-Bleumink M, Berhe D. Occurence of reactions, their diagnosis and managment in leprosy patients treated with multidrug therapy; Experience in the leprosy control program of the All Africa Leprosy and Rehabilitation training Center (ALERT) in Ethiopia. Int J Le pr, 1992; 60: 173-84.

4 Wemambu SNC, Turk JL, Waters MFR. Erytherma Nodosum Leprosum: a clinical manif estation of the Arthus phenomenon. Lancet, 1969; ii: 933-5.

5 Ridley MJ, Ridley DS. The immunopathology of erythema nodosum leprosum: the role of extravascular complexes. Lepr Rev, 1983; 54: 95-107.

6 Abalos RM, Tolentino JG, Bustillo CG. Histochemical study of erythema nodosum leprosum (ENL) lesions. Int J Lepr, 1974; 42: 385-91.

7 Filley E, Andreolli A, Steele J, Rook GAW. A transient rise in agalactosyl IgG correlating with free interleukin-2 receptors during episodes of erythema nodosum. Clin Exp Immunol, 1989; 76: 343-8.

8 Sarno EN, Grau GE, Vieira LM, Nery JA. Serum levels of tumour necrosis factor-alpha and interleukin-1b during leprosy reactional states. Clin Exp Immunol, 1991; 84: 103-8.

9 Iyer CG, Languillon J, Ramanujam K, Tarabini Castellani G, De las Aguas JT, Bechelli LM, Uemura K, Martinez Dominguez V, Sundaresan T. WHO co-ordinated short-term double-blind trial with thalidomide in the treatment of acute lepra reactions in male lepromatous patients. Bull World Hlth Org, 1971; 45(6): 719-32.

${ }^{10}$ Karat AB, Thomas G, Rao PS. Indomethacin in the management of erythema nodosum leprosum-a double-bind controlled trial. Le pr Rev, 1969; 40(3): 153-8.

11 Sarojini PA, Mshana RN. Use of colchicine in the management of erythema nodosum leprosum (ENL). Lepr Rev, 1983; 54(2): 151-3.

12 Kar HK, Roy RG. Comparison of colchicine and aspirin in the treatment of type 2 lepra reaction. Lepr Rev, 1988; 59(3): 201-3.

13 Stanley JNA, Kiran KU, Pearson JMH. The use of colchicine in the management of type 2 lepra reaction (Erythema nodosum leprosum). Le pr Rev, 1984; 55: 317-8.

14 Naafs B. Ratledge C, Stanford J, Grange JM, editors. The biology of the mycobacteria. Volume 3. Clinical aspects of mycobacterial disease. London: Academic Press; 1989; 8, Reactions in leprosy. p. 359-404.

15 Jacobson RR, Hastings RC, editiors. Leprosy. 2nd ed. Edinburgh: Churchill Livingstone; 1994; 16, Treatment of leprosy. p. 338.

16 Bryceson A, Pfaltzgraff RE. Leprosy. 3rd ed. Edinburgh: Churchill Livingstone; 1990.

17 Moreira AL, Sampaio EP, Zmuidzinas A, Frindt P, Smith KA, Kaplan G. Thalidomide exerts its inhibitory action on tumor necrosis factor alpha by enhancing mRNA degradation. J Exp Med, 1993; 177(6): 1675-80.

18 Sampaio EP, Kaplan G, Miranda A, Nery JA, Miguel CP, Viana SM, Sarno EN. The influence of thalidomide on the clinical and immunologic manif estation of erythema nodosum leprosum. $J$ Infect Dis, 1993; 168(2): 408-14.

19 Shannon EJ, Ejigu M, Haile Mariam HS, Berhan TY, Tasesse G. Thalodomide's effectiveness in erythema nodosum leprosum is associated with a decrease in CD4 + cells in the peripheral blood. Le pr Rev, 1992; 63(1): 5-11.

${ }^{20}$ Sheskin J, Convit J. Results of a double-blind study of the influence of thalidomide on the lepra reaction. Int J Lepr Other Mycobact Dis, 1969; 37(2): 135-46.

${ }^{21}$ Sheskin J. Thalidomide in the treatment of lepra reactions. Clinical Pharmacol Therapeutics 1965; 6: $303-6$.

22 Parikh DA, Ganapati R, Revankar CR. Thalidomide in leprosy-study of 94 cases. Ind J Lepr, 1986; 58(4): 560-6.

23 Levy L, Fasal P, Levan NE, Freedman RI. Treatment of erythema nodosum leprosum with thalidomide. Lancet, 1973; ii: 324-5.

24 Waters MF. An internally-controlled double blind trial of thalidomide in severe erythema nodosum leprosum. Lepr Rev, 1971; 42(1): 26-42.

25 Pearson JM, Vedagiri M. Treatment of moderately severe erythema nodosum leprosum with thalidomidea double-blind controlled trial. Le pr Rev, 1969; 40(2): 111-6.

26 Powell RJ, Gardner Medwin JM. Guideline for the clinical use and dispensing of thalidomide. Postgrad Med $J$, 1994; 70(830): 901-4.

27 Powell RJ. New roles for thalidomide. Brit Med J, 1996; 313: 377-8.

28 Awof eso N. Thalidomide peripheral neuropathy. Trop Doct, 1992; 22: 139-40.

29 Waters MFR. Thalidomide peripheral neuropathy. Trop Doct, 1992; 22: 139-40.

30 Sheskin J, Magora A, Sagher F. Motor conduction velocity studies in patients with leprosy reaction treated with thalidomide and other drugs. Int J Lepr Other Mycobact Dis, 1969; 37(4): 359-64.

31 Jakeman P, Smith WCS. Thalidomide in leprosy reaction. Lancet, 1994; 343: 432-3.

32 Browne SG, Hogerzeil LM. B663 in the treatment of leprosy: preliminary report of a pilot trial. Lepr Rev 1962; 33: 6-10. 
${ }^{33}$ Imkamp FM. A treatment of corticosteroid-dependent lepromatous patients in persistent erythema nodosum leprosum. A clinical evaluation of G.30320 (B663). Lepr Rev, 1968; 39(3): 119-25.

${ }^{34}$ Imkamp FM. A treatment of corticosteroid-dependent lepromatous patients in persistent erythema nodosum leprosum with clof azimine. Lepr Rev, 1973; 44(3): 127-30.

${ }^{35}$ Hastings RC, Trautman JR. B663 in lepromatous leprosy. Effect in erythema nodosum leprosum, Lepr Rev, 1968; 39: 3-7.

${ }^{36}$ Helmy HS, Pearson JM, Waters MF. Treatment of moderately severe erythema nodosum leprosum with clof azimine - a controlled trial. Le pr Rev, 1972; 42(3): 167-77.

37 WHO Expert Committee on Leprosy. Fifth Report. Technical Report Series, 1977; 607.

38 Kumar B. Clof azimine-a review. Ind J Le pr, 1991; 63(1): 78-92.

39 Convit J, Soto JM, Sheskin J. Thalidomide therapy in the lepra reaction. Int J Le pr, 1967; 35: 446-51.

40 Rajan MA, Rajagopalan MS, Joseph M. A clinical study of thalidomide requirements comparing pre treatment and post treatment reactional episodes and corticosteroid requirements. Le pr In India, 1983; 55: 111-6.

${ }^{41}$ Pettit JHS. The treatment of erythema nodosum leprosum with B663. A controlled study. Lepr Rev, 1967; 35: $11-6$.

42 Kumar B. Clofazimine-a review. Ind J Lepr, 1991; 63: 78-92.

43 Mishra B, Girdhar BK. Limitations of clof azimine in the treatment of lepra reactions. Ind J Le pr, 1986; 58: 73-8.

${ }^{44}$ Hussain R, Lucas SB, Kifayet A, Jamil S, Raynes J, Uqaili Z, Dockrell HM, Chiang TJ, McAdam KP. Clinical and histological discrepancies in diagnosis of ENL reactions classified by assessment of acute phase proteins SAA and CRP. Int J Lepr Other Mycobact Dis, 1995; 63(2): 222-30.

45 Balow JE. Renal vasculitis. Curr Opin Nephrol Hypertens 1993; 2(2): 231-7.

46 Wallach D. Plasma exchange in severe erythema nodosum leprosum. Int J Artif Organs, 1986; 9: 183-8.

47 Hughes RAC. Intravenous IgG in Guillain-Barre syndrome. Brit Med J, 1996; 313: 376.

48 Jordan SC, Toyoda M. Treatment of autoimmune diseases and systemic vasculitis with pooled human intravenous immune globulin. Clin Exp Immunol, 1994; 97 Suppl 1: 31-8.

49 Mshana RN. Hypothesis: erythema nodosum leprosum is precipitated by an imbalance of T lymphocytes. Lepr Rev, 1982; 53(1): 1-7.

50 Uyemura K, Dixon JF, Wong L, Rea TH, Modlin RL. Effect of cyclosporine A in erythema nodosum leprosum. J Immunol, 1986; 137(11): 3620-3.

51 Miller RA, Shen J, Rea TH, Harnisch JP. Treatment of chronic erythema nodosum leprosum with Cyclosporine A produces clinical and immunohistologic remission. Int J Le pr, 1987; 55: 441-9.

52 Dhainaut JF, Vincent JL, Richard C, Lejeune P, Martin C, Fierobe L, Stephens S, Ney UM, Sopwith M. CDP571, a humanized antibody to human tumor necrosis factor-alpha: saf ety, pharmacokinetics, immune response, and influence of the antibody on cytokine concentrations in patients with septic shock. CPD571 Sepsis Study Group. Crit Care Med, 1995; 23(9): 1461-9.

53 Elliott MJ, Maini RN, Feldmann M, Kalden JR, Antoni C, Smolen JS, Leeb B, Breedveld FC, Macfarlane $\mathrm{JD}, \mathrm{Bijl} \mathrm{H}$, et al. Randomized double-blind comparison of chimeric monoclonal antibody to tumour necrosis factor alpha (cA2) versus placebo in rheumatoid arthritis. Lancet 1994; 344: 1105-10.

${ }^{54}$ Maini RN, Elliott MJ, Brennan FM, Williams RO, Chu CQ, Paleolog E, Charles PJ, Taylor PC, Feldmann M. Monoclonal anti-TNF alpha antibody as a probe of pathogenesis and therapy of rheumatoid disease. Immunol Rev 1995; 144: 195-223.

55 Fekade D, Knox K, Melka A, Lalloo DG, Coxon RE, Warrell DA. Prevention of Jarisch-Herxheimer reactions by treatment with antibodies against tumour necrosis factor $\alpha$. N Engl J Med, 1996; 335: 311-5.

56 Madhok R. Tenidap. Lancet, 1995; 346(8973): 481-5.

57 Mahajan PM, Jadhav VH, Patki AH, Jogaikar DG, Mehta JM. Oral zinc therapy in recurrent erythema nodosum leprosum: a clinical study. Ind J Lepr, 1994; 66(1): 51-7. 